Acta Hispanica (2020) Supplementum II: 795-803

\title{
ENTRADAS DE ORGANIZACIONES LATINOAMERICANAS EN IATE, LA BASE DE DATOS TERMINOLÓGICA DE LA UNIÓN EUROPEA
}

\author{
ESZTER SERMANN
}

Universidad de Szeged

\begin{abstract}
Resumen: El mercado laboral de la mediación lingüística (traducción e interpretación) se ha alargado de manera considerable en las últimas décadas. Durante el proceso de traducción la preparación terminológica de los textos es imprescindible, y para ello las herramientas más útiles y adecuadas son las bases de datos terminológicas disponibles en línea. La base de datos terminológica, por definición, es un conjunto de datos almacenados electrónicamente, elaborada siguiendo un enfoque onomasiológico. Contiene los términos de uno o más dominios, acompañados por sus definiciones en una o más lenguas. Los datos publicados en las bases de datos, preparados por lingüistas en colaboración con los expertos de algún dominio, pueden servir como obras de referencia no solo para mediadores lingüísticos, sino también para profesionales e investigadores. IATE (Interactive Terminology for Europe) es un banco de datos terminológicos del Servicio de Traducción de la Comisión Europea que contiene términos, abreviaturas, acrónimos y fraseología en las lenguas oficiales de la Unión Europea. El objetivo de este estudio es analizar cinco fichas de IATE que representan organizaciones latinoamericanas (Parlamento Latinoamericano, Comunidad Andina, Mercosur, Sistema Económico Latinoamericano y Banco Interamericano de Desarrollo) desde el punto de vista de los datos terminográficos visualizados (término, definición, referencias, contexto, fiabilidad, campo temático). Después de clasificar las herramientas de traducción prestando particular atención a las bases de datos terminológicas (sus características, las normas ISO que describen sus propiedades, las categorías de datos incluidos y los rasgos que las diferencian de los diccionarios en línea), se presentará el análisis de las categorías de datos de las cinco fichas terminográficas.
\end{abstract}

Palabras clave: mediación lingüística, herramientas de traducción, base de datos terminológica, ficha terminográfica, organizaciones latinoamericanas.

Abstract: The labour market for translators and interpreters has lengthened considerably over the
last decades. During translation process, the terminological preparation of texts is essential, and
for this purpose, the most useful and appropriate tools are the online available terminology
databases. The terminology database, by definition, is a set of electronically stored data, which has
been prepared following an onomasiological approach. It contains the terms of one or more
domains, and terms are accompanied by their definitions in one or more languages. The data
published in the databases, which have been prepared by linguists in collaboration with the experts
of the relevant domains, can serve as reference works not only for translators and interpreters,
but also for professionals and researchers. IATE (Interactive Terminology for Europe) is the central
terminology database of the Translation Service of the European Commission, and it contains
terms, abbreviations, acronyms and phraseology in the official languages of the European Union.
The aim of this study is to analyse five IATE entries that represent Latin American organizations
(Latin American Parliament, Andean Community, Mercosur, Latin American Economic System

Acta Hispanica, Hungría, Supplementum II: 795-803, 2020, ISSN: 1416-7263 |795 
Entradas de organizaciones latinoamericanas en IATE,

la base de datos terminológica de la Unión Europea

and Inter-American Development Bank) from the point of view of the visualised terminographic data (e.g. term, definition, references, context, reliability, domain). After the classification of translation tools paying particular attention to terminology databases (their characteristics, the ISO standards that describe their properties, the categories of data included, and the features that differentiate them from online dictionaries), the data categories of the five terminological entries will be analysed.

Keywords: Linguistic Mediation, Translation Tools, Terminological Database, Terminological Entry, Latin American Organizations.

\section{Introducción}

La labor del traductor ha cambiado de manera considerable en las últimas décadas, así actualmente estamos en una época de transición que puede ser similar al paso de la máquina de escribir al ordenador. La máquina de escribir y el diccionario impreso fueron las herramientas de trabajo más utilizadas por los traductores durante décadas, los traductores trabajaban más lentamente que hoy en día. Los tipos de textos para traducir también eran diferentes, en su mayoría se trabajaba con textos literarios. En nuestra época la cantidad de textos especializados para traducir ha aumentado en enormes proporciones en relación con los textos literarios, y las empresas de traducción exigen un trabajo de alta calidad en términos de tiempo muy cortos a los traductores, y su actividad incluye también la pre- y post edición de los resultados de la Traducción Automática. En estas nuevas circunstancias han cambiado también las herramientas de traducción. Durante el proceso de traducción la preparación terminológica de los textos es imprescindible, y para ello las herramientas más útiles y adecuadas son las bases de datos terminológicas disponibles en línea.

Desde el punto de vista de la práctica, los traductores y los intérpretes se denominan mediadores lingüísticos. En Hungría la formación de traductores e intérpretes se realiza dentro de un marco común en las universidades, aunque la práctica de las dos actividades es muy diferente, y exige conocimientos y competencias muy variados por parte de los mediadores lingüísticos. Podemos experimentar considerables diferencias también en el uso de las herramientas tanto en el tiempo, como en el espacio: el intérprete utiliza las herramientas de traducción en la fase preparatoria de su labor, mientras que el traductor tiene posibilidades prácticamente ilimitadas para usarlas. En el presente estudio, cuando se escribe de herramientas de traducción, se hace referencia a las herramientas tanto de los intérpretes, como de los traductores.

El objetivo de este estudio es analizar cinco fichas de IATE que representan organizaciones latinoamericanas (Parlamento Latinoamericano, Comunidad Andina, Mercosur, Sistema Económico Latinoamericano y Banco Interamericano de Desarrollo) desde el punto de vista de los datos terminográficos visualizados (término, definición, referencias, contexto, fiabilidad, campo temático). Después de clasificar las herramientas de traducción prestando particular atención a las bases de datos terminológicas (sus 
características, las normas ISO que describen sus propiedades, las categorías de datos incluidos y, los rasgos que las diferencian de los diccionarios en línea), se presentará el análisis de las categorías de datos de las cinco fichas terminográficas.

\section{Clasificación de las herramientas de traducción}

Las herramientas de traducción pueden clasificarse según diferentes criterios, en el presente estudio se tomará en consideración la siguiente categorización. La primera categoría está formada por los diccionarios impresos, clasificables según el número de lenguas y el campo temático. En el caso de estos productos es fácil controlar la fiabilidad, pero son difíciles de actualizar, y no están siempre al alcance del traductor. El segundo grupo son las herramientas electrónicas: diccionarios electrónicos, que pueden ser en línea o fuera de línea, y las herramientas terminológicas (bancos y bases de datos). La tercera categoría se constituye por las herramientas de traducción asistida por ordenador denominados con el acrónimo CAT (Computer Assisted Translation). Esta última categoría de herramientas incluye los gestores de memorias de traducción, gestores de terminología, alineadores de textos paralelos, herramientas de localización, etc. (Tamás, 2014: 85-86).

Según la definición de Fóris (2007: 301) el diccionario es una base de datos colectiva de una, dos o más lenguas que incluye las características de las unidades lingüísticas según un corpus determinado, bajo varios formatos. Según esta definición, el diccionario en línea pertenece también a esta categoría. En la bibliografía lexicográfica se encuentran diferentes estudios que analizan los diccionarios en línea en comparación con las características de los diccionarios impresos (p. ej. Fóris, 2002, 2005; Gaál, 2016), y podemos encontrar también sistemas de criterios para la evaluación de los diccionarios (p. ej. Fóris - Rihmer, 2007) que se puede aplicar también a los diccionarios en línea.

La base de datos terminológica, por definición, es un conjunto de datos almacenados electrónicamente, elaborada siguiendo un enfoque onomasiológico, un enfoque cuyo punto de partida es el concepto, a diferencia del enfoque semasiológico de los diccionarios. Contiene los términos de uno o más campos temáticos (llamados también dominios en la terminología), acompañados por sus definiciones en una o más lenguas. Los datos publicados en las bases de datos, preparados por lingüistas en colaboración con los expertos de algún dominio, pueden servir como obras de referencia no solo para mediadores lingüísticos, sino también para profesionales e investigadores. Su ventaja es también que son fáciles de acceder y actualizar.

Las primeras bases de datos terminológicas fueron elaboradas en base de diccionarios técnicos impresos con el fin de ofrecer a los traductores herramientas más eficaces que los diccionarios tradicionales (Nkwenti-Azeh, 1998/2001). Las primeras bases de datos nacieron gracias al trabajo de los servicios de traducción, en contacto con diferentes organizaciones, así nacieron las condiciones para poner las bases de la terminología fiable, aceptada, controlable, indispensable para garantizar una consistencia en la traducción y 
Entradas de organizaciones latinoamericanas en IATE,

la base de datos terminológica de la Unión Europea

acelerar el proceso de la traducción (p. ej. EURODICAUTOM - Luxemburgo, TERMIUM - Canadá). Existen diferentes tipos de bases de datos terminológicas, en los últimos años fueron creadas varias bases de datos elaboradas especialmente tomando en consideración las necesidades de los traductores (p. ej. IATE). Prószéky y Kis (1999) afirman que las bases de datos son herramientas indispensables para la traducción especializada, disponen de una interfaz bien definida que se presenta delante del traductor como un diccionario, y facilitan también el registro de nuevos elementos. Las bases de datos incluyen también categorías de datos como la fecha del registro y la última actualización. En varios países se elaboran bases de datos con una ayuda estatal (p. ej. Lituania, Estonia, Dinamarca, etc.). Lamentablemente existen pocas con la lengua húngara, pero serían necesarias en algunos campos temáticos importantes como la informática, la economía, el turismo y la educación.

\section{Las características y la clasificación de las bases de datos terminológicas}

Los diccionarios en línea y las bases de datos terminológicas tienen algunos rasgos comunes y unas diferencias en cuanto a la interfaz y las normas de redacción. La redacción de los diccionarios sigue un método semasiológico cuyo punto de partida es el signo lingüístico, mientras que el método onomasiológico parte del concepto. En el caso del diccionario el elemento central es la palabra, y una entrada enumera los diferentes significados según cierto orden; en las bases de datos el elemento central es el concepto representado por el término y las informaciones adicionales, los datos terminológicos están asignados a los conceptos. También se difieren los tipos de informaciones adicionales, en los diccionarios se ve la pronunciación; en las bases de datos el grado de equivalencia o el grado de aceptabilidad/fiabilidad del término y muchos más que vamos a ver a continuación. Tienen también rasgos comunes: las dos herramientas son en línea, con frecuencia alcanzables gratuitamente, y tienen la ventaja de ser actualizables con facilidad (Tamás, 2014).

Para la redacción de las bases de datos existen recomendaciones de las normas ISO. Las normas ISO nos rodean en la vida cotidiana, existen normas para la traducción, interpretación y también para el trabajo terminológico y la redacción de las bases de datos terminológicas. En las normas podemos encontrar los principios para identificar los conceptos, las relaciones conceptuales, para construir sistemas conceptuales, formular definiciones y términos. Las normas establecen categorías de datos obligatorias (término, definición, la fuente de datos en cada una de las entradas), y categorías de datos adicionales (información gramatical, nivel de equivalencia, dominio, relaciones conceptuales, estructuras conceptuales, notas, información administrativa). Hay que destacar que las reglas redactadas en las normas ISO son recomendaciones, es posible construir bases de datos sin tomar en consideración estas normas (Sermann, 2013).

Tamás (2014) agrupa las bases de datos en tres categorías: (1) simples (p. ej. TERMIUM PLUS), (2) tradicionales (IATE) y (3) complejos (WIPO Pearl, ONU). En el 
caso de las bases de datos simples el número de las categorías de datos no alcanza el mínimo, a veces se trata simplemente de glosarios, y tienen muchas semejanzas con los diccionarios en línea. Las bases de datos clásicas o tradicionales reflejan un enfoque onomasiológico, en que el elemento central es el concepto representado por la definición, a cada concepto está asignado un término y una ficha terminográfica. Una de las características principales de las bases de datos tradicionales es la autonomía del término, es decir, en cada ficha está representado un único término principal, y los eventuales sinónimos aparecen en otra ficha. Los aspectos principales de las bases de datos complejas son idénticos a los de las tradicionales, y además de éstos, contienen elementos adicionales (p. ej. códigos, representaciones gráficas u otras herramientas).

En cuanto a las bases de datos, en la bibliografía relevante podemos encontrar la descripción de diferentes bases de datos (Tamás, 2010, 2014; Sermann, 2011, 2018; Novák, 2018), y varias clasificaciones (Magris - Musacchio, 2002; Sager, 1990; Schmitz Drewer 2017; Tamás, 2014). Sermann y Tamás (2019) describen un sistema de criterios para evaluar y calificar las bases de datos terminológicas, asequibles en línea. Presentan cuatro categorías principales: (1) informaciones sobre los antecedentes de la base de datos (tipo de la organización, asociación o empresa, grupo meta), (2) parámetros técnicos de la base de datos (tipo de software, accesibilidad), (3) informaciones sobre el contenido de la base de datos (estructura detallada), (4) informaciones sobre el uso (actualización, fiabilidad, carácter innovativo, importancia profesional). Utilizando los aspectos del sistema de evaluación es posible calificar, describir, construir bases de datos terminológicas.

\section{Análisis de la estructura de entradas IATE}

IATE es un acrónimo para Interactive Terminology for Europe, un banco de datos terminológicos del Servicio de Traducción de la Comisión Europea que contiene términos, abreviaturas, acrónimos y fraseología en las lenguas oficiales de la Unión Europea. Fue creado en 1999 a través de un proyecto interinstitucional con el fin de crear una infraestructura en la red que albergara todos los recursos terminológicos de la UE. El objetivo de su creación fue recopilar, divulgar y gestionar la terminología específica de la Unión Europea, y el banco de datos se ha venido utilizando en las instituciones y organismos de la UE desde 2004. A partir de noviembre de 2018 se puede usar la nueva versión de IATE, una versión más moderna, que se basa en la tecnología más avanzada.

En el caso de IATE se trata de un banco de datos creado especialmente para traductores y terminólogos de las diferentes instituciones, pero una parte de los datos es pública. El banco de datos sirve como referencia primaria para la traducción de los documentos de la UE, los terminólogos y traductores tienen la obligación de registrar los nuevos términos que surgen en los textos. IATE tiene una interfaz realizada por la UE, y se puede descargar una parte de los datos para integrarlos en herramientas de traducción. Actualmente contiene 7.9 millones de términos en las 24 lenguas oficiales, y

Acta Hispanica, Hungría, Supplementum II: 795-803, 2020, ISSN: 1416-7263 | 799 
Entradas de organizaciones latinoamericanas en IATE, la base de datos terminológica de la Unión Europea

además, en ciertos campos temáticos, incluye términos en latín. La base de datos tiene un papel crucial en el establecimiento de la equivalencia entre los términos que abundan en los documentos multilingües, indispensables para el funcionamiento de la Unión Europea. La estructura de las entradas terminológicas es jerárquica, refleja un enfoque onomasiológico, las informaciones relacionadas al concepto se presentan en tres niveles: en el nivel independiente de la lengua, en el nivel lingüístico y en el del término. En realidad, el nivel independiente de la lengua es el del concepto: aquí se describe el campo temático, el origen de concepto, el país o la cultura con la que el concepto está relacionado. El nivel lingüístico forma un nivel intermediario entre el concepto y el término, aquí se añade todo tipo de información adicional relacionada al concepto come bibliografía, fuente e imágenes. En el nivel del término se encuentran los términos en diferentes lenguas, los datos gramaticales, notas y el código de fiabilidad (Lesznyák, 2010). En la interfaz de usuario se puede elegir la lengua del banco de datos, pero entrando desde un dominio español la lengua de la interfaz se convierte en español automáticamente. Entre los criterios de la búsqueda los siguientes son obligatorios: expresión, lengua de origen, lengua(s) meta. Además de los criterios obligatorios, podemos encontrar otros opcionales: campos temáticos representados por códigos, y podemos efectuar la búsqueda dentro de un único campo temático. Al final, podemos marcar también el tipo de búsqueda: expresión, abreviación, etc. La nueva interfaz de usuario del banco de datos es fácil de usar, los datos son regularmente actualizados.

Observando las fichas terminográficas de IATE podemos ver que el formato de las entradas no es uniforme: hay fichas con un número limitado de categorías de datos, p. ej. falta la definición, y en su lugar se presenta un contexto, mientras que otras fichas están bien elaboradas con definición, contexto y otros datos adicionales. El objetivo del presente estudio es analizar algunas entradas de IATE que representan organizaciones latinoamericanas (Parlamento Latinoamericano, Comunidad Andina, Mercosur, Sistema Económico Latinoamericano, Banco Interamericano de Desarrollo) desde el punto de vista de los datos terminográficos visualizados (término, definición, referencias, contexto, fiabilidad, campo temático). El estudio se enfoca en la presencia o falta de las categorías obligatorias según la normas ISO (término, definición, referencia de la definición) y de las eventuales categorías adicionales (contexto, campo temático, información gramatical). Los resultados del análisis se ven en la tabla $\mathrm{I}$. 
Eszter Sermann

\begin{tabular}{|l|c|c|c|c|c|}
\hline Categorías de datos & $\begin{array}{c}\text { Parlamento } \\
\text { Latino- } \\
\text { americano }\end{array}$ & $\begin{array}{c}\text { Comunidad } \\
\text { Andina }\end{array}$ & Mercosur & $\begin{array}{c}\text { Sistema } \\
\text { Económico } \\
\text { Latino- } \\
\text { americano }\end{array}$ & $\begin{array}{c}\text { Banco } \\
\text { Interamericano } \\
\text { de Desarrollo }\end{array}$ \\
\hline Término (O) & + & + & + & + & + \\
\hline Definición (O) & + & + & + & - & + \\
\hline $\begin{array}{l}\text { Referencia de la } \\
\text { definición (O) }\end{array}$ & + & + & + & - & + \\
\hline Contexto (A) & - & + & - & - & + \\
\hline Fiabilidad (A) & + & + & + & + & + \\
\hline $\begin{array}{l}\text { Forma corta/ } \\
\text { Abreviación (A) }\end{array}$ & + & + & - & + & + \\
\hline $\begin{array}{l}\text { Campo temático } \\
\text { (A) }\end{array}$ & + & + & + & + & + \\
\hline $\begin{array}{l}\text { Referencia de uso } \\
\text { (A) }\end{array}$ & - & - & + & - & + \\
\hline
\end{tabular}

Tabla I. Resultado del análisis de cinco fichas terminográficas IATE que representan organizaciones latinoamericanas

Las categorías obligatorias según la norma ISO (marcadas con la O) son el término, la definición y la referencia de la definición, mientras que las otras categorías (marcadas con la A) son adicionales: contexto, fiabilidad, forma corta/abreviación, campo temático, referencia de uso. Podemos ver que no todas las fichas siguen las recomendaciones de las normas ISO, porque en el caso del Sistema Económico Latinoamericano falta tanto la definición como el contexto. En cuanto a las categorías adicionales, la presencia de datos no es uniforme. La fiabilidad no es una categoría obligatoria según la norma ISO, pero lo es según las prescripciones de IATE, por lo tanto, este criterio aparece en cada una de las fichas terminográficas. A cada uno de los términos está asignado un grado de fiabilidad indicado con asteriscos de 1 a 5, donde uno significa poco fiable, cinco, muy fiable. El campo temático en cada uno de los casos es el derecho, organizaciones latinoamericanas. La referencia de uso se presenta solamente en una ficha, las demás entradas no incluyen este tipo de información. En resumen, podemos decir que en el caso de las fichas de las cinco organizaciones analizadas no son uniformes, se presentan diferentes categorías de datos, y no siguen las prescripciones de las normas ISO, sino otro tipo de reglas fijadas por la Unión Europea. Las categorías de datos comunes para todas las fichas analizadas son las siguientes: término, fiabilidad, campo temático. 
Entradas de organizaciones latinoamericanas en IATE, la base de datos terminológica de la Unión Europea

\section{Conclusión}

Las bases de datos terminológicas son herramientas fiables e útiles de los traductores, porque contienen no solo las informaciones gramaticales básicas relacionadas con los términos, sino también facilitan el análisis conceptual necesario para la traducción de los términos. En el presente estudio se ha realizado el análisis de cinco fichas IATE que representan organizaciones latinoamericanas (Parlamento Latinoamericano, Comunidad Andina, Mercosur, Sistema Económico Latinoamericano y Banco Interamericano de Desarrollo) desde el punto de vista de los datos terminográficos visualizados (término, definición, referencias, contexto, fiabilidad, campo temático). Después de una clasificación de las herramientas de traducción prestando particular atención a las bases datos terminológicas (sus características, las normas ISO que describen sus propiedades, las categorías de datos incluidos y, los rasgos que las diferencian de los diccionarios), la descripción de la estructura y el contenido de IATE, el banco de datos de las instituciones de la UE, han sido presentados los resultados del análisis de las categorías de datos de las cinco fichas terminográficas. Como hemos visto IATE ofrece una pluralidad de datos, es una herramienta útil no solo para los traductores e intérpretes, sino también para los expertos y profesionales de diferentes campos temáticos.

\section{Referencias bibliográficas}

Fóris, Ágota (2007). A szótár terminus értelmezéséről. En: Magay, Tamás (ed.). Félmúlt és közeljövó. (Lexikográfiai füretek 3.), Budapest: Akadémiai Kiadó, 295-302.

Fóris, Ágota (2005). Hat terminológia lecke. Pécs: Lexikográfia Kiadó.

Fóris, Ágota (2002). Szótár és oktatás. Pécs: Lexikográfia Kiadó.

Fóris, Ágota - Rihmer, Zoltán (2007). A szótárak minősítési kritériumairól. Fordítástudomány IX/1. 109-113.

Gaál, Péter (2016). Online szótárak és has₹nálóik. Onlineszótár-használati kutatások, online szótárak értékelési és minösitési szempontjai. Doktori dissz̧ertáció. Pécs: PTE.

Lesznyák, Ágnes (2010). Az európai uniós intézmények terminológiai adatbázisa: a IATE. Magyar Terminológia, 3/2. 161-181.

Magris, Marella - Musacchio, Maria Teresa et al. (eds.) (2002.) Manuale di terminologia. Milano: Hoepli.

Nkwenti-Azeh, Blaise (1998/2001). Term banks. En: Baker, Mona (1998/2001). (ed.). Routledge Encyclopedia of Translation Studies. London/New York: Routledge. 249-251.

Novák, Barnabás (2018). A terminológiai munkafolyamat a minôségi jogalkotásban. Magyar-olasz. összehasonlitó vizssgálat az alkotmányjogi terminológia területén. [Tesis doctoral]. Pécs: PTE. 
Prószéky, Gábor - Kis, Balázs (1999). A számitógéppel emberi nyelven. Intelligens szövegkęelés számitógéppel. Bicske: SZAK Kiadó.

Sager, Juan C. (1990). A practical course in terminology processing. Amsterdam/Philadelphia: John Benjamins Publishing Company.

Schmitz, Klaus-Dirk - Drewer, Petra (2017). Terminologiemanagement. Grundlagen, Methoden, Werkzenge. Berlin: Springer Vieweg Verlag.

Sermann, Eszter (2018). Terminológiai adatbázisok mint a nyelvi korlátok áthidalásának eszközei. Magyar nyelven (is) elérhetó néhány terminológiai adatbázis tartalmi és szerkezeti vizsgálata. Acta Historiae Litterarum Hungaricarum. Acta Universitatis Szegediensis, 34./3. 149-169.

Sermann, Eszter (2013). A terminológiai szabványositás és a terminológiai harmonizáció forditási vonatkozásai. [Tesis doctoral]. Budapest: ELTE.

Sermann, Eszter (2011). A terminológiai szabványosítás szerepe a lokalizáció folyamatában. Fordítástudomány. XIII/2. 72-87.

Tamás, Dóra (2010). La knowledge base EOHS Term, ossia un vocabolario online creativo. En: Dávid, Gábor Csaba - Zelényi, Annamária (eds.). 2010. Corvinus nyelvi napok, "Kreativitás és nyelv". 2009. szeptember 23-24. Budapesti Corvinus Egyetem IOK Alkalmazott Nyelvészeti Kutató- és Továbbképző Központ. Budapest: Aula Kiadó. 349355.

Tamás, Dóra Mária (2014). Gazdasági szakszövegek forditásának terminológiai kérdéseiról. Budapest: ELTE Bölcsészettudományi Kar Fordító- és Tolmácsképző Tanszék.

Tamás, Dóra Mária - Sermann, Eszter (2019). Elemzési szempontrendszer terminológiai adatbázisokhoz. Fordítástudomány XXI/2. 46-62.

\section{Bases de datos terminológicas en línea}

EUROTERMBANK https://www.eurotermbank.com/, fecha de consulta: 01-10-2019. IATE https:/ / iate.europa.eu; https://iate.europa.eu/home, fecha de consulta: 01-10-2019. Termium Plus https://www.btb.termiumplus.gc.ca, fecha de consulta: 01-10-2019. WIPO Pearl https://www.wipo.int, fecha de consulta: 01-10-2019. 